\title{
Implementing and integrating a clinically driven electronic medical record for radiation oncology in a large medical enterprise
}

\author{
John P. Kirkpatrick ${ }^{1}{ }^{*}$, Kim L. Light ${ }^{1}$, Robyn M. Walker ${ }^{1}$, Debra L. Georgas ${ }^{1}$, Phillip A. Antoine ${ }^{1}$, \\ Robert W. Clough ${ }^{1}$, Heidi B. Cozart ${ }^{2}$, Fang-Fang Yin ${ }^{1}$, Sua Yoo ${ }^{1}$ and Christopher G. Willett ${ }^{1}$ \\ 1 Department of Radiation Oncology, Duke University, Durham, NC, USA \\ ${ }^{2}$ Duke Health Technology Solutions, Duke University, Durham, NC, USA
}

Edited by:

Edward Sternick, Rhode Island

Hospital, USA

Reviewed by:

Kathryn Huber, Tufts Medical Center

USA

Skye Hung-Chun Cheng, Koo

Foundation Sun Yat-Sen Cancer

Center, Taiwan

*Correspondence:

John P. Kirkpatrick, Duke University

Medical Center, Durham, NC 27710,

USA.

e-mail: john.kirkpatrick@dm.duke.edu

Portions of this study were presented at the 52nd Annual Meeting of the

American Society of Radiation

Oncology, October, 2010, and the

36th Annual Meeting of the American

Association of Medical Dosimetrists,

June, 2011.
Purpose/Objective:While our department is heavily invested in computer-based treatment planning, we historically relied on paper-based charts for management of Radiation Oncology patients. In early 2009 , we initiated the process of conversion to an electronic medical record (EMR) eliminating the need for paper charts. Key goals included the ability to readily access information wherever and whenever needed, without compromising safety, treatment quality, confidentiality, or productivity.

Methodology: In February, 2009, we formed a multi-disciplinary team of Radiation Oncology physicians, nurses, therapists, administrators, physicists/dosimetrists, and information technology (IT) specialists, along with staff from the Duke Health System IT department. The team identified all existing processes and associated information/reports, established the framework for the EMR system and generated, tested and implemented specific EMR processes.

Results: Two broad classes of information were identified: information which must be readily accessed by anyone in the health system versus that used solely within the Radiation Oncology department. Examples of the former are consultation reports, weekly treatment check notes, and treatment summaries; the latter includes treatment plans, daily therapy records, and quality assurance reports. To manage the former, we utilized the enterprisewide system, which required an intensive effort to design and implement procedures to export information from Radiation Oncology into that system. To manage "Radiation Oncology" data, we used our existing system (ARIA, Varian Medical Systems.) The ability to access both systems simultaneously from a single workstation (WS) was essential, requiring newWS and modified software. As of January, 2010, all new treatments were managed solely with an EMR. We find that an EMR makes information more widely accessible and does not compromise patient safety, treatment quality, or confidentiality. However, compared to paper charts, time required by clinicians to access/enter patient information has substantially increased. While productivity is improving with experience, substantial growth will require better integration of the system components, decreased access times, and improved user interfaces. \$127K was spent on new hardware and software; elimination of paper yields projected savings of $\$ 21 \mathrm{~K} /$ year. One year after conversion to an EMR, more than $90 \%$ of department staff favored the EMR over the previous paper charts.

Conclusion: Successful implementation of a Radiation Oncology EMR required not only the effort and commitment of all functions of the department, but support from senior health system management, corporate IT, and vendors. Realization of the full benefits of an EMR will require experience, faster/better integrated software, and continual improvement in underlying clinical processes.

Keywords: electronic medical record, electronic health record, quality assurance, patient safety, radiation oncology practice, charts, information technology

\section{INTRODUCTION}

As a medical specialty, radiation oncology relies heavily on technology for planning and treating cancer patients. While a variety of information and practice management systems are available (e.g., ARIA from Varian Medical Systems, Palo Alto, CA, USA and Mosaiq from Elekta, Stockholm, Sweden), these systems are specific to radiation oncology and are quite difficult to integrate with enterprise-wide information systems. Thus, 
radiation oncology departments have typically generated and utilized department-specific paper charts, containing planning and treatment data unique to radiation oncology, as well as demographic and disease-specific information for a particular patient. As a result, much of the information in the radiation oncology chart was essentially inaccessible to other practitioners in the health system or duplicated information in the enterprise-wide medical system and the planning/treatment data base. As an example, the historical organization of information in our department is shown in Table 1.

In 2007, we recognized that an electronic medical record (EMR) could offer an improved ability to distribute and access radiation oncology planning, treatment, and patient management information throughout our enterprise. In addition, we saw potential benefits within the department from an EMR, including improved access to information, i.e., no more need to locate the paper chart, and decreased expenses associated with creation, storage, and retrieval of paper charts. At the same time, we appreciated that the paper chart offered many desirable attributes, including ready access to radiation oncology planning/treatment information in a single place and a high level of comfort with its use on the part of radiation oncology providers. Nonetheless, we concluded that an EMR was inevitable and potentially a significant advance.

This paper presents our experience with development of a radiation oncology EMR in the Duke University Health System, an enterprise that is composed of over 1,500 practitioners with more than two million patient visits annually.

\section{MATERIALS AND METHODS}

In developing the goals of the goals and objectives for a radiation oncology EMR, departmental, and health system leadership agreed that the EMR must have the attributes shown in Table 2.

It was clear that we must continue to provide safe and effective treatment of our patients, and, in doing so, that we comply with all regulatory policies and principles of good medical practice. The EMR must also facilitate communication within the department and throughout the organization. As one senior thoracic surgeon stated, "When a patient receiving radiation for lung cancer shows up in the emergency department in the middle of the night, I need to know right then and there what you [Radiation Oncology] have been doing to him." Thus, the information in the EMR would have to be immediately and easily accessible to whomever needs it, wherever and whenever necessary. As discussed below, this required that we identify what information is needed by whom.

While we recognized that work flow would change with implementation of an EMR, we established an objective that the EMR should not require a net effort greater than that of the existing process. Finally, the project was constrained by the requirement that we utilize the existing ARIA radiation oncology and enterprise-wide information technology (IT) infrastructure without significant expenditures.

To meet the above ambitious goals, we established a formal project guided by the following set of principles (Table 3 ).

While the above list appears straightforward, a great deal of debate went into its creation. At the outset of this, some argued that we start with a "blank slate," i.e., design an ideal information
Table 1 | Distribution of patient/treatment information in our department pre-implementation of a radiation oncology EMR.

\begin{tabular}{lll}
\hline RadOnc paper chart & Enterprise-wide EMR & ARIA/eclipse \\
\hline Consult note & Consult note & Planning orders \\
RT prescription & Lab reports & RT prescription \\
Treatment plans & Radiology reports & Treatment plans \\
Path reports & Path reports & Daily treatment log \\
Treatment & Treatment & QA reports \\
summary & summary & \\
Weekly notes & Follow-up notes & Task pad \\
Consents & Consents & RadOnc schedules \\
Vitals and some & Medications and & \\
medications & some vitals & \\
\end{tabular}

Bold face indicates documents that appear in multiple information systems.

Table 2 | Required attributes for the radiation oncology EMR.

Does not compromise safe/effective treatment of patients

Ensures integrity of patient data

Complies with government/institution requirements for documentation

and billing

HIPAA compliant

Facilitates communication internally and externally

EMR is accessible to whomever needs this information at all times

Requires less net effort than existing paper chart

Utilizes existing ARIA and enterprise-wide internet/information system

No major software/hardware purchases

Table 3 | EMR project principles.

Start with existing chart and most important processes

Replace current processes with "electronic version"

BUT, automate data entry and transfer where possible

Shoot for workable (as opposed to perfect) solution

Test as we go along

Processes will be "designed/built" through EMR team at central campus

Communicate to department continually

Create buy-in

BUT, no one allowed to "opt out" of EMR

Establish firm deadline for conversion to EMR

system and then build and/or select the system that best meets those specifications. However, given the constraints that we utilize existing systems, minimize expenditures, and meet deadline for implantation, we instead chose to strive for a "less-than-perfect" solution that was workable and implementable. Specifically, we elected not to design a system which automatically stores all patient and treatment-related data in a readily queryable database, facilitating our research mission.

In order to effectively implement the EMR, it was clear that we needed to create consensus from all stakeholders. To do so, multiple discussions and meetings were held throughout the department. Nonetheless, several senior staff argued that establishing an EMR was unnecessary, wasteful of time and money, 
a diversion of attention from patient care, and/or of unproven benefit. Despite these objections and a suspicion on many members of the department that "some people will never use an EMR," senior leadership unambiguously communicated that there was no option to "opt out" of using an EMR after it was established.

The importance of setting an achievable, but firm, deadline for conversion to an EMR at the outset of the project is paramount. Once in place, the sanctity of this deadline must be reinforced at all levels continually, and project milestones created and progress measured against this deadline.

Given the broad impact of an EMR, we created the following project team composed of all departmental stakeholders, as well as a representative from the health system IT group (Table 4).

The team met weekly or biweekly, depending on the tasks at hand, and was led by the Clinical Director and the Chair of the department. Prior to each meeting a detailed agenda was distributed, along with minutes from the previous meeting. These minutes, which were generated by a dedicated scribe, contained a point-by-point summary of items discussed at the meeting along with action items specifying timing and responsibility.

In addition to the team members, it was also essential to secure the commitment of senior hospital administration and our radiation oncology software vendor (Varian) to the success of this project.

\section{RESULTS}

The EMR project was initiated in February, 2008, with a deadline for implementation of January, 2009. On January 4, 2009, the department converted from paper charts to the EMR.

To meet the specifications, a virtual radiation oncology chart was designed, composed of two primary systems (Table 5 below).

Information that would be utilized only in radiation oncology, e.g., treatment planning orders, dose distributions, etc., would be placed in ARIA. In contrast, any information that would be potentially needed outside of Radiation Oncology, e.g., consultation notes, weekly on-treatment visit notes, consents for treatment, would reside in the enterprise-wide information system eBrowser (McKesson, San Francisco, CA, USA).

Management of external documents was a major issue in developing the above system. With a paper chart, external documents, such as outside pathology, radiology, and operative reports, were filed in the radiation oncology chart. After extensive discussions, the hospital leadership approved scanning these documents and internal hand-completed forms, such as patient intake questionnaires and treatment consents, into eBrowser. Access to these documents was substantially facilitated by placing them with clear titles in eBrowser, e.g., "External Radiology Report."

The detailed location of specific documents in the EMR is shown in Table 6.

Utilizing the EMR required installation of patient information network (PIN) workstations in every exam room and physician work room to provide ready provider access to eBrowser. In addition, working with Varian, we installed access to ARIA/Eclipse via a Citrix-server on the PIN workstations. Thus, providers have the full capabilities of the virtual radiation oncology chart from any PIN workstation.

Table 4 | Composition of radiation oncology EMR team.

Departmental administration

Administrative assistants, medical records, schedulers, operations

management

Departmental information technology

Dosimetry

Hospital IT

Nursing

Physicians

Physics

Radiation therapists

Table 5 | Virtual radOnc chart: ARIA + eBrowser.

Utilize ARIA for radiation oncology-specific processes, e.g.

Treatment planning orders

Radiation therapy prescription

Workflow management

Treatment plan with approvals

Characterized by specialized information neededonly within RadOnc

Utilize eBrowser for all other info, e.g.

Consult notes, treatment summaries

Weekly treatment check notes, nursing notes

Treatment planning/simulation notes

Consents, patient intake forms

Selected outside data

Characterized by any information needed outside of RadOnc

Table 6 | Location of specific documents in the virtual radiation oncology chart.

\section{ARIA}

Treatment planning orders

Radiation therapy

prescription

Treatment record

Radiation therapy notes

Planning/treatment tasks

QA documentation

On-treatment images

2D/electron calculations

\section{Eclipse}

Contours

Treatment plans (dose

distribution/DVH)
eBrowser

Consultation notes*

RadOnc weekly on-treatment

notes*

Treatment planning/sim note*

Nursing notes*

Treatment summary*

Patient intake questionnaire**

Consents**

Internal lab, pathology, radiology, procedure reports*

External documents**

PACS

Diagnostic radiology images

*Directly entered into eBrowser; ** scanned into eBrowser.

One year after implementation of the radiation oncology EMR, a web-based survey of the department revealed a high level of satisfaction with the EMR (Table 7). Of the 70 respondents, 81 and $78 \%$ agreed that the EMR had improved the quality of patient care and patient safety, respectively. Ninety percent of respondents agreed that EMR improved the quality of medical records versus paper charts while only $25 \%$ agreed that information was harder 
Table 7 | Results of a web-based survey of the Duke radiation oncology department on the EMR, conducted 1 year after conversion from paper charts to the EMR.

\begin{tabular}{|c|c|c|c|c|c|c|c|c|}
\hline Question & $\begin{array}{l}\text { Disagree } \\
\text { Completely } \\
=1\end{array}$ & $\begin{array}{l}\text { Disagree } \\
\text { Somewhat } \\
=\mathbf{2}\end{array}$ & $\begin{array}{c}\text { Neither } \\
\text { Agree nor } \\
\text { Disagree }=3\end{array}$ & $\begin{array}{l}\text { Agree } \\
\text { Somewhat } \\
=4\end{array}$ & $\begin{array}{l}\text { Agree } \\
\text { Completely } \\
=5\end{array}$ & $\begin{array}{c}\text { Don't } \\
\text { Know } \\
\text { (Not rated) }\end{array}$ & $\begin{array}{c}\text { Total } \\
\text { Responses }\end{array}$ & $\begin{array}{c}\text { Average } \\
\text { Rating }\end{array}$ \\
\hline \multirow{2}{*}{$\begin{array}{l}\text { EMR has improved the quality } \\
\text { of patient care. }\end{array}$} & 0 & 1 & 12 & 28 & 29 & 0 & 70 & \multirow{2}{*}{4.21} \\
\hline & $0 \%$ & $1 \%$ & $17 \%$ & $40 \%$ & $41 \%$ & $0 \%$ & & \\
\hline \multirow{2}{*}{$\begin{array}{l}\text { EMR has improved patient } \\
\text { safety. }\end{array}$} & 0 & 3 & 8 & 24 & 31 & 4 & 70 & \multirow{2}{*}{4.01} \\
\hline & $0 \%$ & $4 \%$ & $11 \%$ & $34 \%$ & $44 \%$ & $6 \%$ & & \\
\hline \multirow{2}{*}{$\begin{array}{l}\text { With EMR, I have less time to } \\
\text { spend on patient care/quality. }\end{array}$} & 13 & 13 & 21 & 15 & 7 & 0 & 69 & \multirow{2}{*}{2.86} \\
\hline & $19 \%$ & $19 \%$ & $30 \%$ & $22 \%$ & $10 \%$ & $0 \%$ & & \\
\hline \multirow{2}{*}{$\begin{array}{l}\text { EMR has improved the quality } \\
\text { of medical records vs the paper } \\
\text { chart. }\end{array}$} & 0 & 4 & 3 & 21 & 42 & 0 & 70 & \multirow{2}{*}{4.44} \\
\hline & $0 \%$ & $6 \%$ & $4 \%$ & $30 \%$ & $60 \%$ & $0 \%$ & & \\
\hline \multirow{2}{*}{$\begin{array}{l}\text { It is harder to find patient } \\
\text { information with the EMR than } \\
\text { with paper chart. }\end{array}$} & 26 & 22 & 5 & 11 & 6 & 0 & 70 & \multirow{2}{*}{2.27} \\
\hline & $37 \%$ & $31 \%$ & $7 \%$ & $16 \%$ & $9 \%$ & $0 \%$ & & \\
\hline \multirow{2}{*}{$\begin{array}{l}\text { With EMR, I can get the same } \\
\text { amount of work done in less } \\
\text { time. }\end{array}$} & 7 & 24 & 13 & 14 & 10 & 1 & 69 & \multirow{2}{*}{2.90} \\
\hline & $10 \%$ & $35 \%$ & $19 \%$ & $20 \%$ & $14 \%$ & $1 \%$ & & \\
\hline \multirow{2}{*}{$\begin{array}{l}\text { EMR has made communication } \\
\text { more difficult and less effective } \\
\text { within the Department. }\end{array}$} & 21 & 24 & 13 & 9 & 2 & 1 & 70 & \multirow{2}{*}{2.20} \\
\hline & $30 \%$ & $34 \%$ & $19 \%$ & $13 \%$ & $3 \%$ & $1 \%$ & & \\
\hline \multirow{2}{*}{$\begin{array}{l}\text { EMR has made Chart QA more } \\
\text { difficult }\end{array}$} & 18 & 14 & 8 & 14 & 5 & 11 & 70 & \multirow{2}{*}{2.16} \\
\hline & $26 \%$ & $20 \%$ & $11 \%$ & $20 \%$ & $7 \%$ & $16 \%$ & & \\
\hline \multirow{2}{*}{$\begin{array}{l}\text { EMR has made it easier to } \\
\text { comply with HIPAA }\end{array}$} & 3 & 3 & 22 & 19 & 15 & 8 & 70 & \multirow{2}{*}{3.23} \\
\hline & $4 \%$ & $4 \%$ & $31 \%$ & $27 \%$ & $21 \%$ & $11 \%$ & & \\
\hline
\end{tabular}

\section{If I had to choose the EMR versus a paper chart system, I would choose:}

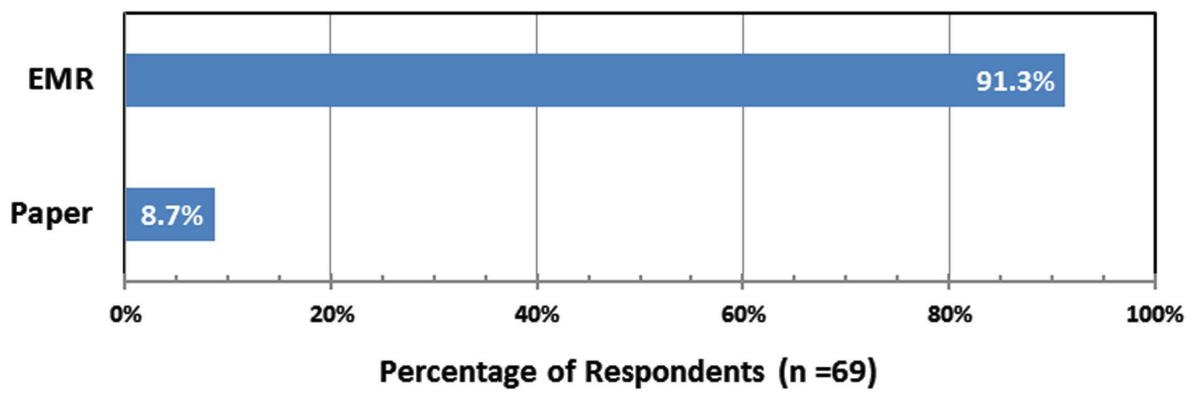

FIGURE 1 | Responses from a web-based survey of the Duke Radiation Oncology Department, conducted 1 year after conversion from paper charts to the EMR.

to find in the medical record. However, only $34 \%$ of those surveyed agreed that they got the same amount of work done in less time with the EMR. When asked if they had to choose between the EMR and a paper chart, which they would select, 63 of 69 respondents (91\%) chose the EMR (Figure 1).
Though practitioners out side the department were not queried using a questionnaire, we rarely, if ever, receive complaints about a lack of information on a patient's plan for or progress during a course of radiation therapy No significant safety or quality problems attributable to the EMR have been observed. Between 
2008 and 2010, the rate of treatment deviations (as a percentage of patients treated) fell from 0.24 to $0.12 \%$.

\section{DISCUSSION}

Timely, appropriate and clear communication and documentation is a fundamental requirement of radiation oncology practice (Martin, 1999; Bria II and Shabot, 2005; IMRT Documentation Working Group et al., 2009; Bleich and Slack, 2010; Moran et al., 2011; American Society for Radiation Oncology, 2012; Chera et al., 2012). An EMR offers the promise of improving the effectiveness and efficiency of communications, documentation, work flow, and ultimately, patient care (Salenius et al., 1992; Sailer et al., 1997; Law, 2005; Middleton et al., 2009). Moreover, an EMR will essentially be required in the United States in order to meet the requirements of various federal initiatives, avoiding penalties for non-compliance (Centers for Medicare \& Medicaid Services, and HHS, 2012; Office of the National Coordinator for Health Information Technology, 2012; Shen et al., 2012). Of course, while an EMR can be a valuable component of a radiation oncology's quality and safety program, other aspects of the program are at least as important, including establishing a culture that fosters safety and quality, exercising leadership on these issues, and utilizing the optimum combination of new technology, tried-and-true clinical practices, and commonsense (Bleich and Slack, 2010; Marks et al., 2011; American Society for Radiation Oncology, 2012; Chera et al., 2012; Pawlicki et al., 2012).

Implementation of the EMR in our department was accomplished on-time without compromising patient safety or treatment quality. While the capital outlay for new hardware and software modifications was minimal $(\$ 127,000)$, we estimate that over 1,000 h of effort was expended in designing, executing, and implementing this project - much of it from radiation oncology clinic staff (Table 8). These costs are partially offset by a reduction in annual costs of paper and supplies to create these charts ( $\sim 21,000$ /year.) In addition, there are less well-quantified savings associated with the reduced need to file charts and newly received documents, balanced by the cost of scanning documents into the enterprise-wide system. The EMR clearly eliminates the problem of "misplaced" charts and provides ready access to all information, but this access can be hampered by the need for multiple logins (common), slow hardware/software/internet speeds (variable severity and intermittent), and system outages (rare).

\section{REFERENCES}

American Society for Radiation Oncology. (2012). Safety is No Accident: A Framework for Quality Radiation Oncology and Care. Fairfax: ASTRO.

Bleich, H. L., and Slack, W. V. (2010). Reflections on electronic medical records: when doctors will use them and when they will not. Int. J. Med. Inform. 79, 1-4.

Bria, W. F. II, and Shabot, M. M. (2005). The electronic medical record, safety, and critical care. Crit. Care Clin. 21, 55-79, viii.

Centers for Medicare \& Medicaid Services, and HHS. (2012). Medicare

Table 8 |The "balance sheet" for our radiation oncology EMR.

\begin{tabular}{ll}
\hline Plus & Minus \\
\hline $\begin{array}{ll}\text { Annual paper/supply savings: \$21K } \\
\text { No lost charts }\end{array}$ & $\begin{array}{r}\text { One-time capital costs: \$127K } \\
+1000 \text { 's of man-hours invested } \\
\text { Hardware/software downtime }\end{array}$ \\
$\begin{array}{l}\text { anformation accessible anywhere, } \\
\text { Filing eliminated }\end{array}$ & Slow information retrieval \\
$\begin{array}{l}\text { Compliant with policies, safe practice } \\
\text { Disruptive }\end{array}$ & $\begin{array}{l}\text { Software not fully compatible } \\
\text { Learning curve (slightly) painful }\end{array}$ \\
& Disruptive
\end{tabular}

Designing/selecting and implementing a radiation oncology EMR that is compatible with a health system's information system is a disruptive process. Clearly, the disruption of existing practices has cost associated with changing practices, new infrastructure, and the replacement of the familiar paper charts. If conversion to an EMR is poorly executed (or communicated), this disruption can lead to degraded quality or unsafe conditions. On the other hand, disruption in this situation can have long-term benefits if it forces us to question our existing practices, consider the unfamiliar and adopt improved practices, procedures, and technologies. Finally, the most meaningful question is whether an "EMR helps deliver better quality and/or more cost effective health care." This is an important, difficult question and, to our knowledge, there is not yet an objective answer (Menachemi and Collum, 2011).

\section{CONCLUSION}

Successful and safe implementation of a Radiation Oncology EMR can be accomplished with minimal capital costs in a reasonable time-frame given complete commitment and substantial effort from the department and the support of senior management, the enterprise-wide IT department, and information system vendors. Full realization of the clinical benefits of an EMR will require experience, faster/better integrated software, continual improvement in underlying clinical processes and objective analysis of costs and savings. We believe that the structure for the Radiation Oncology EMR described in this paper is compatible and be integrated with the electronic health record system (Epic, Verona, WI, USA) being adopted by our health system.

therapy treatments. Int. J. Radiat. Oncol. Biol. Phys. 74, 1311-1318.

Law, M. Y. (2005). A model of DICOMbased electronic patient record in radiation therapy. Comput. Med. Imaging Graph 29, 125-136.

Marks, L. B., Rose, C. M., Hayman, J. A., and Williams, T. R. (2011). The need for physician leadership in creating a culture of safety. Int. J. Radiat. Oncol. Biol. Phys. 79, 1287-1289.

Martin, L. A. (1999). Essentials of radiation oncology chart design. Med. Dosim. 24, 39-41.

Menachemi, N., and Collum, T. H. (2011). Benefits and drawbacks of electronic health record systems. Risk Manag. Healthc. Policy 4, 47-55.

Middleton, M., Bradford, C., Frantzis, J., Ambler, A., Sisson, T., Montgomerie, D., et al. (2009). Paperless and paper-based processes in the modern radiotherapy department. Radiography 15, 300-305.

Moran, J. M., Dempsey, M., Eisbruch, A., Fraass, B. A., Galvin, J. M., Ibbott, G. S., et al. (2011). Safety considerations for IMRT: executive summary. Med. Phys. 38, 5067-5072.

Office of the National Coordinator for Health Information Technology, 
Centers for Medicare \& Medicaid Services, and Department of Health and Human Services. (2012). Health information technology: revisions to the 2014 edition electronic health record certification criteria; and medicare and medicaid programs; revisions to the electronic health record incentive program. Interim final rule with comment period. Fed. Regist., 77, 72985-72991.

Pawlicki, T., Chera, B., Ning, T., and Marks, L. B. (2012). The systematic application of quality measures and process control in clinical radiation oncology. Semin. Radiat. Oncol. 22, 70-76.
Sailer, S. L., Tepper, J. E., MargoleseMalin, L., Rosenman, J. G., and Chaney, E. L. (1997). RAPID: an electronic medical records system for radiation oncology. Semin. Radiat. Oncol. 7, 4-10.

Salenius, S. A., Margolese-Malin, L., Tepper, J. E., Rosenman, J., Varia, M., and Hodge, L. (1992). An electronic medical record system with direct data-entry and research capabilities. Int. J. Radiat. Oncol. Biol. Phys. 24, 369-376.

Shen, X., Dicker, A. P., Doyle, L., Showalter, T. N., Harrison, A. S., and DesHarnais, S. I. (2012). Pilot study of meaningful use of electronic health records in radiation oncology. J. Oncol. Pract. 8, 219-223.

Conflict of Interest Statement: The authors declare that the research was conducted in the absence of any commercial or financial relationships that could be construed as a potential conflict of interest.

Received: 20 February 2013; accepted: 18 March 2013; published online: 18 April 2013.

Citation: Kirkpatrick JP, Light KL, Walker RM, Georgas DL, Antoine $P A$, Clough RW, Cozart HB, Yin FF, Yoo S and Willett CG (2013) Implementing and integrating a clinically driven electronic medical record for radiation oncology in a large medical enterprise. Front. Oncol. 3:69. doi: 10.3389/fonc.2013.00069

This article was submitted to Frontiers in Radiation Oncology, a specialty of Frontiers in Oncology.

Copyright (C) 2013 Kirkpatrick, Light, Walker, Georgas, Antoine, Clough, Cozart, Yin, Yoo and Willett. This is an open-access article distributed under the terms of the Creative Commons Attribution License, which permits use, distribution and reproduction in other forums, provided the original authors and source are credited and subject to any copyright notices concerning any third-party graphics etc. 